\title{
A Novel Hybrid Nanosystem Integrating Cytotoxic and Magnetic Properties as a Tool to Potentiate Melanoma Therapy
}

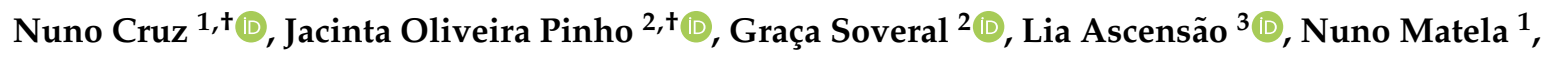 \\ Catarina Reis ${ }^{1,2, *(1)}$ and Maria Manuela Gaspar ${ }^{2, *}$ \\ 1 Instituto de Biofísica e Engenharia Biomédica (IBEB), Faculdade de Ciências, Universidade de Lisboa, \\ Campo Grande, 1749-016 Lisboa, Portugal; nunocruz9009@gmail.com (N.C.); nmatela@fc.ul.pt (N.M.) \\ 2 Research Institute for Medicines, iMed.ULisboa, Faculty of Pharmacy, Universidade de Lisboa, Av. Prof. \\ Gama Pinto, 1649-003 Lisboa, Portugal; jopinho@ff.ulisboa.pt (J.O.P.); gsoveral@ff.ulisboa.pt (G.S.) \\ 3 Centro de Estudos do Ambiente e do Mar (CESAM), Faculdade de Ciências, Universidade de Lisboa, Campo \\ Grande, 1749-016 Lisboa, Portugal; lmpsousa@fc.ul.pt \\ * Correspondence: mgaspar@ff.ulisboa.pt (M.M.G.); catarinareis@ff.ulisboa.pt (C.R.); \\ Tel.: +351-217-946-400 (ext. 14774 or 14244) (M.M.G. \& C.R.); Fax: +351-217-946-470 (M.M.G. \& C.R.) \\ + These authors contributed equally to this work.
}

Received: 29 February 2020; Accepted: 31 March 2020; Published: 6 April 2020

\begin{abstract}
Cancer is a major health concern and the prognosis is often poor. Significant advances in nanotechnology are now driving a revolution in cancer detection and treatment. The goal of this study was to develop a novel hybrid nanosystem for melanoma treatment, integrating therapeutic and magnetic targeting modalities. Hence, we designed long circulating and $\mathrm{pH}$-sensitive liposomes loading both dichloro(1,10-phenanthroline) copper (II) (Cuphen), a cytotoxic metallodrug, and iron oxide nanoparticles (IONPs). The synthetized IONPs were characterized by transmission electron microscopy and dynamic light scattering. Lipid-based nanoformulations were prepared by the dehydration rehydration method, followed by an extrusion step for reducing and homogenizing the mean size. Liposomes were characterized in terms of incorporation parameters and mean size. High Cuphen loadings were obtained and the presence of IONPs slightly reduced Cuphen incorporation parameters. Cuphen antiproliferative properties were preserved after association to liposomes and IONPs (at $2 \mathrm{mg} / \mathrm{mL}$ ) did not interfere on cellular proliferation of murine and human melanoma cell lines. Moreover, the developed nanoformulations displayed magnetic properties. The absence of hemolytic activity for formulations under study demonstrated their safety for parenteral administration. In conclusion, a lipid-based nanosystem loading the cytotoxic metallodrug, Cuphen, and displaying magnetic properties was successfully designed.
\end{abstract}

Keywords: Cuphen; iron oxide nanoparticles; $\mathrm{pH}$-sensitive liposomes; magnetic targeting; melanoma therapy; nanoparticles safety

\section{Introduction}

Melanoma, which derives from the malignant transformation of melanocytes, is one of most aggressive forms of skin cancer [1]. Treatment options are primarily based on surgery, radiotherapy and chemotherapy. When the disease is detected at an early stage, the cure is often possible with surgery. However, when it progresses to the metastatic phase, the prognosis is poor, with low survival rates, and therapy usually fails. In these particular situations, combined systemic approaches are implemented, including targeted or non-targeted immunotherapy, chemo or and/or hormonal therapies [2-4]. Despite 
some improved clinical responses, the survival rates are still very low $[5,6]$, motivating the development of novel or more effective therapeutic approaches.

The clinical success of cisplatin, a Pt(II) complex, against several tumors has prompted the investment on coordination chemistry of metal-based drugs for cancer [7]. In recent years, metal-based compounds, namely gold and copper complexes [8-15], have been researched as anticancer agents. Copper-phenanthroline compounds were shown to promote oxidative DNA damage [16], and $\mathrm{Cu}^{2+}$ compounds, including dichloro(1,10-phenanthroline) copper (II), Cuphen have also been reported as inhibitors of aquaporin-3 (AQP3), an aquaglyceroporin that is overexpressed in several carcinomas including melanoma $[17,18]$. Previously, Cuphen has demonstrated potent in vitro cytotoxic effects against murine and human melanoma cells lines, with an half-inhibitory concentration under $3.5 \mu \mathrm{M}$ in all tested lines $[8,9]$. Considering the in vivo setting, to minimize potential unwanted side effects in non-affected and to protect the metallodrug from premature degradation, Cuphen was associated with long circulating liposomes, a well-known drug delivery nanosystem $[8,9]$. Studies in healthy mice revealed no toxic effects after parenteral administration of Cuphen liposomes, demonstrating their safety [8].

The use of nanosized liposomes with prolonged circulation times in the blood is advantageous for targeting tumor sites, as the possibility to extravasate to affected areas increases and due to a deficient lymphatic drainage, liposomes accumulate. This phenomenon has been known as enhanced permeation and retention (EPR) effect [19-21]. In addition, solid tumors, such as melanoma, are characterized by a slightly acidic microenvironment, displaying $\mathrm{pH}$ values around 6 [22,23]. In order to take advantage of this feature and promote a local $\mathrm{pH}$-triggered Cuphen release, Pinho and colleagues [9] evaluated the therapeutic effect of Cuphen liposomal formulations in a murine melanoma model, comparing $\mathrm{pH}$-sensitive with non $\mathrm{pH}$ sensitive nanoformulations. The results showed a significant inhibition of tumor growth progression, compared to control group and animals receiving Cuphen in free form [9].

Following these promising results, the next step was to further enhance the accumulation and of Cuphen liposomes at melanoma sites through magnetic targeting. Magnetic iron oxide nanoparticles (IONPs) have been used for several applications in medicine, including cancer treatment via thermal ablation or hyperthermia [24], theranostics [25], as well as magnetically targeted drug carriers [26-28]. Hence, in order to potentiate melanoma therapy, the aim of the present study was to develop a new hybrid lipid-based nanosystem co-loading Cuphen, the cytotoxic metallodrug, and IONPs, for magnetic targeting as schematically demonstrated in Figure 1.

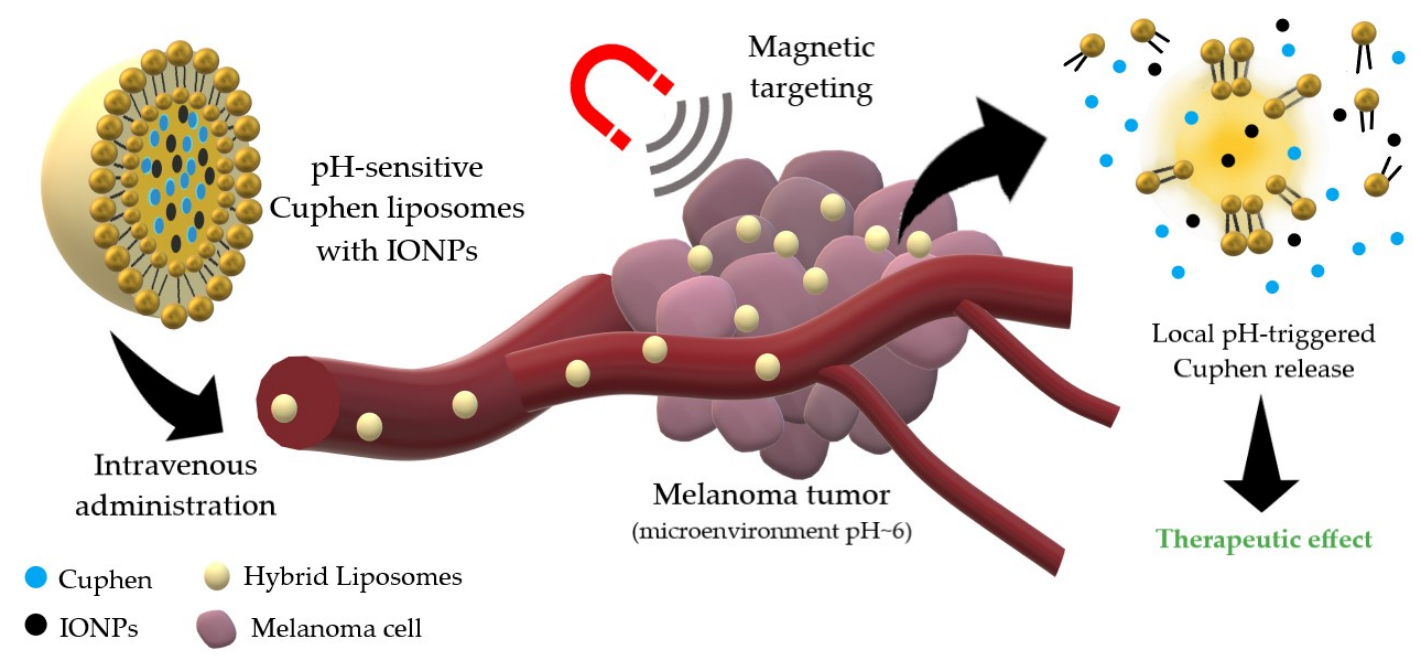

Figure 1. Schematic representation of the hybrid nanosystem integrating cytotoxic and magnetic properties as a tool to potentiate melanoma therapy. 


\section{Materials and Methods}

\subsection{Chemicals}

Hydrazine Monohydrate $\left(\mathrm{H}_{4} \mathrm{~N}_{2} \cdot \mathrm{H}_{2} \mathrm{O}\right)$, Dextran-70 $\left(\mathrm{H}_{(}\left(\mathrm{C}_{6} \mathrm{H}_{10} \mathrm{O}_{5}\right)_{70} \mathrm{OH}\right)$ and Ferric Chloride $\left(\mathrm{FeCl}_{3}\right)$ were obtained from Sigma (Sigma-Aldrich, St. Louis, MO, USA). The lipids dimiristoyl phosphatidyl choline (DMPC), cholesteryl hemisuccinate (CHEMS) and distearoyl phosphatidylethanolamine covalently linked to poly (ethylene glycol) 2000 (DSPE-PEG) were obtained from Avanti Polar Lipids (AL, USA). Dichloro(1,10-phenanthroline) copper (II) (Cuphen) was obtained from Sigma (Sigma-Aldrich, St. Louis, MO, USA). All other reagents were of analytical grade.

\subsection{Cell Line Culture Conditions}

B16F10 and MNT-1 cell lines were maintained in Dulbecco's Modified Eagle's medium (DMEM) with high glucose $(4500 \mathrm{mg} / \mathrm{L})$, supplemented with $10 \%$ fetal bovine serum and $100 \mathrm{IU} / \mathrm{mL}$ of penicillin and $100 \mu \mathrm{g} / \mathrm{mL}$ streptomycin.

\subsection{IONPs Synthesis}

Dextran-coated IONPs were produced following a previously described method [29], with some modifications in order to allow the use of Dextran-70 instead of Dextran-10 [30]. To produce Dextran-70 coated IONPs, $\mathrm{FeCl}_{3}(76 \mathrm{mg})$ and Dextran-70 $(100 \mathrm{mg})$ were added to $8 \mathrm{~mL}$ of bidistilled water. The mixture was then placed into a reaction vial and stirred to promote dissolution. To the obtained solution, $1 \mathrm{~mL}$ of $\mathrm{H}_{4} \mathrm{~N}_{2} \cdot \mathrm{H}_{2} \mathrm{O}$ was added under stirring and, subsequently, placed into the Anton Paar Monowave 300 reaction chamber (Graz, Austria), at a temperature of $100{ }^{\circ} \mathrm{C}$ for $10 \mathrm{~min}$. Uncoated particles were produced following the same procedure, except no Dextran-70 was added to the initial solution. The uncoated particles were separated from the solvent by centrifugation at $2200 \mathrm{~g}$ for $8 \mathrm{~min}$ (Sigma 2020-MK, St. Louis, MO, USA). The coated particles were subjected to dialysis using a dialysis sleeve (Medicell Int. LTD, London, UK, 12,000-14,000 MWCO) to remove any unreacted components remaining in suspension. The obtained IONPs were lyophilized during $24 \mathrm{~h}$ at $-50{ }^{\circ} \mathrm{C}$ (freeze-dryer model, Edwards, CO, USA). Particle morphology and size were assessed by transmission electron microscopy (TEM) and dynamic laser scattering (DLS), respectively.

\subsection{IONPS Characterization by TEM and DLS}

Samples of Dextran-70 coated and uncoated IONPs were prepared for morphological analysis through the negative staining method. IONPs were resuspended in distilled water and droplets $(10 \mu \mathrm{L})$ were placed on Formvar-carbon-coated grids. After a few minutes, during which the particles attach to the Formvar-carbon film, the grids were partially dried with a piece of filter paper. The material was then negatively stained with $1 \%$ uranyl acetate and left to dry at room temperature. Observations were carried out on a JEOL 1200EX transmission electron microscope (JEOL Ltd., Tokyo, Japan) at an accelerating voltage of $80 \mathrm{kV}$. Images were recorded digitally. The mean hydrodynamic size and polydispersivity index (PDI) of the IONPs was assessed by the DLS equipment Zetasizer Nano $S$ (Malvern Instruments, Inc., Malvern, UK).

\subsection{Preparation of Liposomes}

Long circulating and pH-sensitive liposomes with the lipid composition composed of dimiristoyl phosphatidyl choline (DMPC), cholesteryl hemisuccinate (CHEMS), and distearoyl phosphatidylethanolamine covalently linked to poly (ethylene glycol) 2000 (DSPE-PEG), DMPC:CHEMS:DSPE-PEG, at a molar ratio of 57:38:5, were prepared by the dehydration-rehydration method [8,9,31]. An initial lipid concentration of $30 \mu \mathrm{mol} / \mathrm{mL}$ was used. Briefly, the selected phospholipids were dissolved in chloroform in a round-bottomed flask. The obtained lipid solution was evaporated (Buchi R-200 rotary evaporator, Flawil, Switzerland) to form a thin lipid film, which 
was then dispersed with (i) a Cuphen aqueous solution $(750 \mu \mathrm{M})$ and (ii) a Cuphen and Dextran-70 coated IONPs aqueous solution at a final concentration of $750 \mu \mathrm{M}$ and $2 \mathrm{mg} / \mathrm{mL}$, respectively. The so-formed suspensions were frozen $\left(-70^{\circ} \mathrm{C}\right)$ and lyophilized overnight. The lyophilized products were rehydrated in HEPES buffer, pH $7.4(10 \mathrm{mM}$ HEPES, $145 \mathrm{mM} \mathrm{NaCl})$ in two steps, to enhance compound incorporation [32]. Afterwards, all liposomal suspensions were filtered under nitrogen pressure (10-500 lb/in2) through polycarbonate membranes of proper pore size until the desired vesicle size was obtained, using an extruder apparatus (Lipex: Biomembranes Inc., Vancouver, BC, Canada). Non-incorporated Cuphen and IONPs were separated by gel filtration (BioRad Econo-Pac ${ }^{\circledR}$ 10DG). The suspension was concentrated using a benchtop centrifuge at 15,000 $\mathrm{g}$ for $30 \mathrm{~min}$ (Sigma 2020-MK). In the case of Cuphen liposomes, the suspension was ultracentrifuged in a Beckman LM-80 ultracentrifuge (Beckman Instruments, Inc., Fullerton, CA, USA) at 250,000 $\mathrm{g}$, for $120 \mathrm{~min}$. The pellets were suspended in HEPES buffer.

\subsection{Liposomes Characterization}

Liposomes were characterized in terms of Cuphen incorporation parameters and mean size by DLS (Zetasizer Nano S, Malvern, UK). Initial and final loading capacity was defined as the initial Cuphen to lipid ratio (Cuphen/Lip) and final Cuphen to lipid ratio (Cuphen/Lip)f, respectively.

Cuphen was quantified spectrophotometrically at $270 \mathrm{~nm}\left(\varepsilon=33,000 \mathrm{M}-1 \mathrm{~cm}^{-1}\right)$ after disruption of the liposomes with absolute ethanol [8,9]. The linearity of calibration curves was confirmed from 2.5 to $25 \mu \mathrm{M}\left(\mathrm{R}^{2}=0.9998\right.$; Slope: $0.0324 \pm 0.0001$; $\mathrm{y}$-intercept $[\mathrm{x}=0$ ]: $-0.0036 \pm 0.0006)$. Lipid content was determined using the method described by Rouser [33].

The determination of the percentage of the hybrid nanosystem that precipitates using a benchtop centrifuge or an ultracentrifuge was performed according to Equation (1):

$$
\text { Precipitated Hybrid nanosystem }(\%)=\frac{\text { Lipid in pellet }(\mu \mathrm{mol})}{\text { Total Lipid }(\mu \mathrm{mol})} \times 100
$$

\subsection{Cytotoxicity Studies}

Murine (B16F10) and human (MNT-1) cell viability was evaluated in the absence (control) or presence of increasing concentrations of Cuphen and Dextran-70 coated IONPs, alone or in combination, in free forms, by the MTT assay. Cells were placed in 96-well plates $(200 \mu \mathrm{L})$, at a concentration of $5 \times$ $10^{4}$ cells $/ \mathrm{mL}$ and allowed to grow for $24 \mathrm{~h}$, at $37^{\circ} \mathrm{C}, 5 \% \mathrm{CO}_{2}$ [9]. Next, complete culture medium was replaced, and cells treated with the formulations under study: (i) Cuphen at concentrations ranging from 0.5 to $7 \mu \mathrm{M}$; (ii) IONPs at concentration values from 1 to $7.5 \mathrm{mg} / \mathrm{mL}$; and (iii) combination of Cuphen $(1$ and $5 \mu \mathrm{M})$ with IONPs at $2 \mathrm{mg} / \mathrm{mL}$. Cells with only complete culture medium constituted the controls. Following the $24 \mathrm{~h}$ incubation period, complete medium was discarded and, to each well, $50 \mu \mathrm{L}$ of MTT reagent $(0.5 \mathrm{mg} / \mathrm{mL}$ in incomplete culture medium) was added. After an incubation period of 3-4 h, $100 \mu \mathrm{L}$ of DMSO were added to each well to dissolve the formazan crystals. Absorbance was measured at $570 \mathrm{~nm}$ in a microplate reader (Model 680, Bio-Rad, Hercules, CA, USA). Cell proliferation was analyzed in GraphPad Prism ${ }^{\circledR} 5$ (GraphPad Software, San Diego, CA, USA). Values were plotted and fit to a standard inhibition log dose response curve to generate the $\mathrm{IC}_{50}$ values. A total of three independent experiments, with six replicates per condition, were carried out.

\subsection{Magnetism Assays}

For this in vitro test, NdFeB magnets (José Teixeira da Rocha, Unipessoal, Lda.; N38, stacked: $40 \times$ $10 \times 20 \mathrm{~mm}, 560.9 \mathrm{mT}$ ) were used. Briefly, $1.5 \mathrm{~mL}$ of Cuphen and IONPs liposomal suspension were placed in a 6-well plate. The magnet was positioned below the well containing the sample, at one of the extremities. Following the designated times of 1, 2, 4 and $19 \mathrm{~h}$, magnetic exposure was ceased and samples $(100 \mu \mathrm{L})$ from the magnet region and opposite extremity were collected. Cuphen contents were determined as described above. 


\subsection{Hemolysis Assays}

The hemolytic activity of Cuphen and Dextran-70 coated IONPs, in free and liposomal forms, was assessed using EDTA-preserved peripheral human blood [31], obtained from a voluntary donor. Serum was removed by centrifugation at $1000 \mathrm{~g}$ for $10 \mathrm{~min}$ and the erythrocyte suspension was washed three-times with PBS at $1000 \mathrm{~g}$ for $10 \mathrm{~min}$. The formulations under study were diluted in PBS and distributed in 96-well plates (100 $\mu \mathrm{L} /$ well), for final concentrations ranging from 3.125 to $200 \mu \mathrm{M}$ and 0.313 to $5 \mathrm{mg} / \mathrm{mL}$, for Cuphen and IONPs, respectively. Then, $100 \mu \mathrm{L}$ of erythrocyte suspension was added to all samples, followed by an incubation at $37^{\circ} \mathrm{C}$ for $1 \mathrm{~h}$ and centrifugation at $800 \mathrm{~g}$ for $10 \mathrm{~min}$. Supernatants were collected and the absorbance was measured at $550 \mathrm{~nm}$, with a reference filter at $620 \mathrm{~nm}$. The hemolytic activity in percentage for each tested sample was calculated comparing each individual determination to positive control (100\% hemolysis, erythrocytes in distilled water) and negative control (erythrocytes in PBS), according to Equation (2):

$$
\text { Hemolysis }(\%)=\frac{(\mathrm{AbsS}-\mathrm{AbsN})}{(\mathrm{AbsP}-\mathrm{AbsN})} \times 100,
$$

where AbsS is the average absorbance of the sample, AbsN is the average absorbance of the negative control and AbsP is the average absorbance of the positive control.

\section{Results}

\subsection{Characterization of IONPS}

Dextran-coated and uncoated IONPs were produced following a previously described method [29], with some modifications. The obtained particles were characterized in terms of morphology by TEM and size by DLS for coated IONPs. As shown in Figure 2a, uncoated IONPs displayed an increased aggregation and a larger iron core compared to the Dextran-70 coated IONPs in Figure 2b, which were homogeneously dispersed. The same effect was observed by Oliveira, et al. 2019, when preparing uncoated IONPs [34]. Furthermore, since Dextran-70 was attached to the IONPs' surface, the size of the whole particle was assessed by DLS, with values of $105 \pm 2 \mathrm{~nm}$ and a PDI of $0.238 \pm 0.009$. In the following sections, Dextran-70 coated IONPs, the selected nanoparticles for the conducted studies, will be simply designated by IONPs.

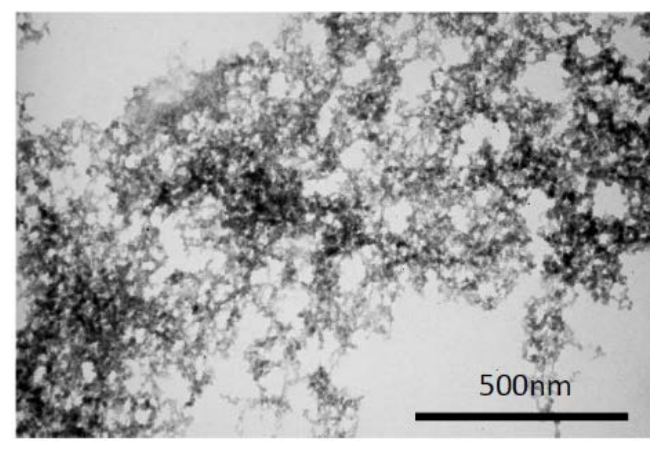

(a)

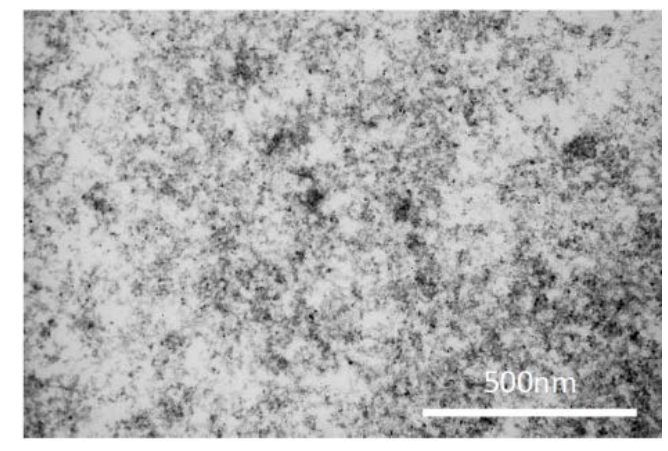

(b)

Figure 2. Representative TEM images of (a) uncoated iron oxide nanoparticles (IONPs) and (b) Dextran-70 coated IONPs. Scale bar $=500 \mathrm{~nm}$.

\subsection{Cytotoxicity of Cuphen and IONPS}

The antiproliferative activity of free Cuphen and IONPs, alone and in combination, was evaluated by MTT assay in human (MNT-1) and murine (B16F10) melanoma cell lines (Figure 3). Data in Figure $3 b, c$ show that Cuphen decreased cell viability of melanoma cell lines in a dose-dependent manner. For the tested cell lines, $\mathrm{IC}_{50}$ values below the micromolar range $(<10 \mu \mathrm{M})$ were obtained: 
$4.3 \pm 0.1 \mu \mathrm{M}$ and $5.7 \pm 0.8 \mu \mathrm{M}$ for MNT-1 and B16F10, respectively. Although a slight loss of cell viability for B16F10 was obtained for higher concentrations, Figure 3d, no appreciable cytotoxic effects were observed for IONPs concentrations of 1 and $2 \mathrm{mg} / \mathrm{mL}$ for both cell lines. According to these data, cell viability was evaluated after incubation with IONPs, at the selected concentration of $2 \mathrm{mg} / \mathrm{mL}$, in combination with Cuphen at concentrations of 1 and $5 \mu \mathrm{M}$, Figure $3 \mathrm{e}$. The results revealed that the presence of IONPs, at the tested concentration, did not affect the cytotoxic properties of Cuphen, thus rendering their co-loading in liposomes feasible.

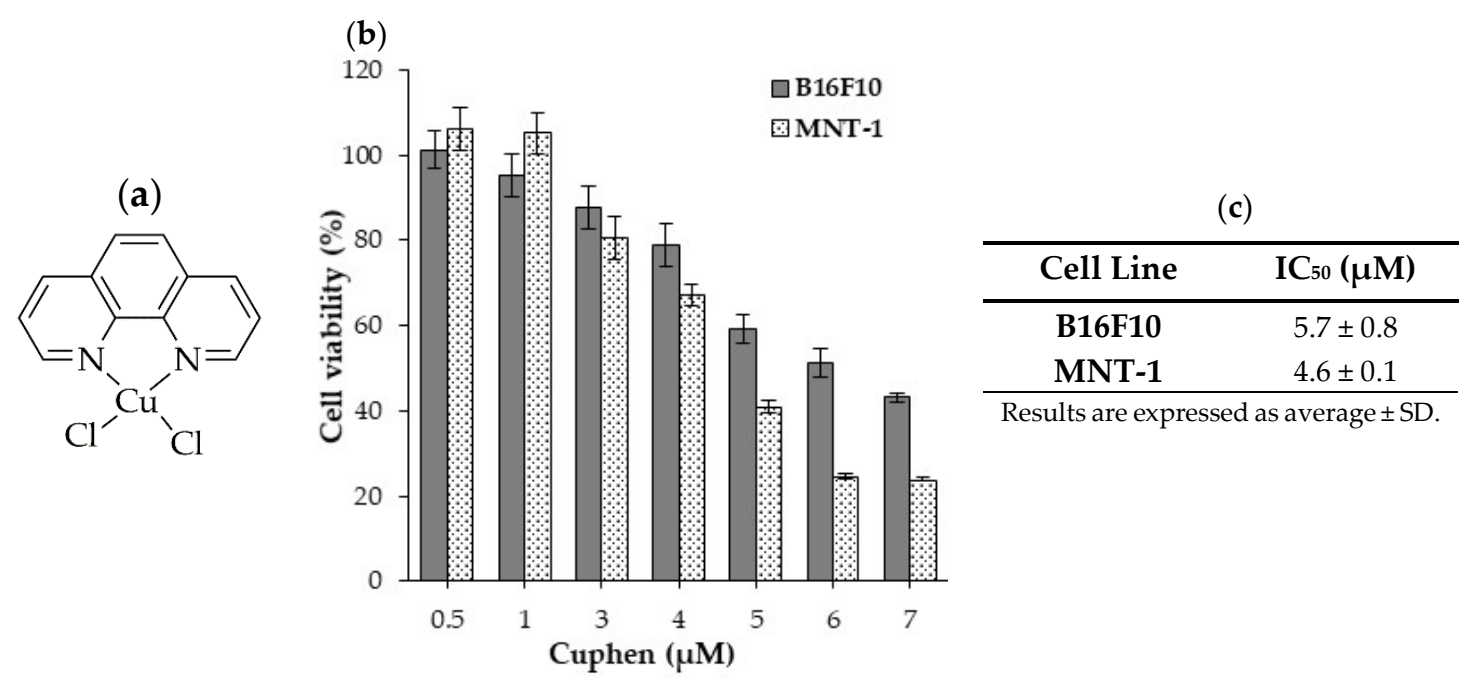

(d)

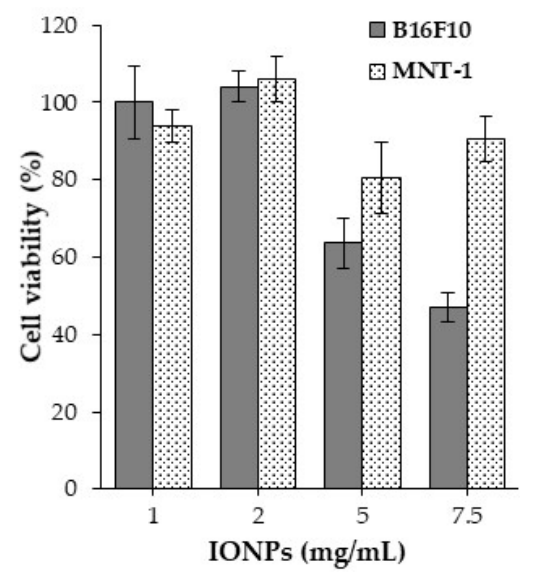

(e)

\begin{tabular}{|c|c|c|c|c|c|}
\hline \multirow{2}{*}{$\begin{array}{l}\text { Cell } \\
\text { Line }\end{array}$} & \multicolumn{2}{|c|}{ Cuphen $1 \mu \mathrm{M}$} & \multicolumn{2}{|c|}{ Cuphen $5 \mu \mathrm{M}$} & \multirow{2}{*}{$\begin{array}{c}\text { IONPs } \\
(2 \mathrm{mg} / \mathrm{mL})\end{array}$} \\
\hline & $\begin{array}{l}\text { Without } \\
\text { IONPs }\end{array}$ & $\begin{array}{l}\text { With } \\
\text { IONPs }\end{array}$ & $\begin{array}{l}\text { Without } \\
\text { IONPs }\end{array}$ & $\begin{array}{l}\text { With } \\
\text { IONPs }\end{array}$ & \\
\hline $\mathrm{B} 16 \mathrm{~F} 10$ & $104 \pm 4$ & $102 \pm 2$ & $65 \pm 2$ & $66 \pm 2$ & $106 \pm 3$ \\
\hline MNT-1 & $106 \pm 5$ & $107 \pm 5$ & $59 \pm 2$ & $62 \pm 2$ & $105 \pm 5$ \\
\hline
\end{tabular}

Figure 3. Evaluation of Cuphen and IONPs cytotoxic activity towards human (MNT-1) and murine (B16F10) melanoma cell lines. (a) Cuphen chemical structure; (b) cell viability after $24 \mathrm{~h}$ incubation with different Cuphen concentrations $(0.5$ to $7 \mu \mathrm{M})$; (c) Cuphen half-inhibitory concentration $\left(\mathrm{IC}_{50}\right)$ values; (d) cell viability after $24 \mathrm{~h}$ incubation with IONPs at a concentration ranging from 1 to $7.5 \mathrm{mg} / \mathrm{mL}$; (e) cell viability after a $24 \mathrm{~h}$ incubation period with Cuphen $(1$ and $5 \mu \mathrm{M})$ in the presence or absence of IONPs at a concentration of $2 \mathrm{mg} / \mathrm{mL}$. Data are expressed as mean percentage (\%) of control $\pm \mathrm{SD}$ of three independent experiments with six replicates each.

\subsection{Liposomes Co-Loading Cuphen and IONPS}

Liposomes with the lipid composition DMPC:CHEMS:DSPE-PEG (57:38:5), which display $\mathrm{pH}$-sensitive properties, were prepared by the dehydration-rehydration method [9]. On one hand, nanosized liposomes require long ultracentrifugation cycles $(\geq 2 \mathrm{~h}, 250,000 \mathrm{~g})$ to precipitate [8]. On the other hand, IONPs easily precipitate in short centrifugation cycles using a benchtop centrifuge. In this sense, the encapsulation of IONPs in liposomes was indirectly confirmed by quantification of lipid 
content (\%) of liposomes that precipitated under the experimental conditions depicted in Table 1. A total amount of $10 \mu \mathrm{mol}$ of lipid was used in all experiments and the content in the pellet was determined for both centrifugation conditions and expressed in $\mu \mathrm{mol}$ and percentage.

Table 1. Size and lipid content of liposomes co-loading IONPs and Cuphen before and after short centrifugation cycles.

\begin{tabular}{|c|c|c|c|}
\hline $\begin{array}{c}\text { DMPC:CHEMS:DSPE-PEG } \\
(57: 38: 5)\end{array}$ & $\begin{array}{c}\varnothing \\
(\mathrm{nm})\end{array}$ & PDI & $\begin{array}{l}\text { Lipid }(\mu \mathrm{mol}) \\
(\%)\end{array}$ \\
\hline Before centrifugation & $163 \pm 2$ & $0.06 \pm 0.02$ & $\begin{array}{c}10 \\
(100 \%)\end{array}$ \\
\hline $\begin{array}{l}\text { Centrifugation } \\
15,000 \mathrm{~g}, 30 \mathrm{~min}\end{array}$ & $176 \pm 2$ & $0.06 \pm 0.02$ & $\begin{array}{l}5.8 \pm 0.1 \\
(59 \%)\end{array}$ \\
\hline $\begin{array}{l}\text { Ultracentrifugation } \\
42,000 \mathrm{~g}, 20 \mathrm{~min}\end{array}$ & $175 \pm 1$ & $0.08 \pm 0.01$ & $\begin{array}{l}5.6 \pm 0.2 \\
(54 \%)\end{array}$ \\
\hline \multicolumn{4}{|c|}{$\begin{array}{l}\text { Values are expressed as average } \pm \text { SD of at least two independent } \\
\text { experiments. DMPC: dimiristoyl phosphatidyl choline; CHEMS: } \\
\text { cholesteryl hemisuccinate; DSPE-PEG: distearoyl } \\
\text { phosphatidylethanolamine covalently linked to poly(ethylene) glycol } \\
\text { 2000; PDI: polidispersity index. Ø: mean size of liposomes. }\end{array}$} \\
\hline
\end{tabular}

As shown in Table 1, more than $50 \%$ of liposomes precipitated by both short centrifugation cycles, confirming that IONPs were associated with the nanosystem.

As both centrifugation conditions led to equivalent results, for nanoformulations co-loading Cuphen and IONPs, the centrifugation cycle of 15,000 $\mathrm{g}$ for $30 \mathrm{~min}$ was selected to evaluate if Cuphen liposomes with the same lipid composition would show the same pattern. As depicted in Figure 4a no pellet was obtained, reinforcing the fact that Cuphen liposomes would only precipitate when co-loaded with IONPs (Figure $4 b$ ).

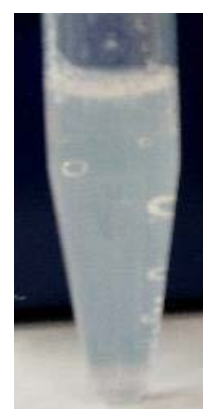

(a)

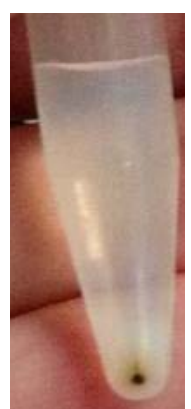

(b)

Figure 4. Representative images of (a) Cuphen liposomes and (b) liposomes co-loading Cuphen and IONPs, after a centrifugation cycle of $15,000 \mathrm{~g}, 30 \mathrm{~min}$.

\subsection{Influence of IONPs on the Physicochemical Parameters of Cuphen Liposomes}

Cuphen nanoformulations were prepared with and without IONPs and their presence on the physicochemical properties of Cuphen liposomes was evaluated. The obtained results are shown on Table 2. Aiming to maximize the loading of IONPs, the influence of two different liposomal formulations LIP A and LIP B, with sizes $<200 \mathrm{~nm}$ and $<300 \mathrm{~nm}$, respectively were tested. In all the developed nanoformulations, the presence of IONPs affected Cuphen incorporation parameters, leading to a reduction on the loading capacity and an increase of the mean size. With IONPs, LIP A displayed a loading capacity of $22 \mathrm{nmol} / \mu \mathrm{mol}$, contrasting with the values of $26 \mathrm{nmol} / \mu \mathrm{mol}$ for Cuphen liposomes. The same tendency was obtained for LIP B, with loading capacity values of 25 and $35 \mathrm{nmol} / \mu \mathrm{mol}$, respectively. Although LIP A and LIP B were produced under the same experimental 
conditions, a systematic increase on the mean size of nanoformulations co-loading Cuphen and IONPs was observed. For LIP A and LIP B, an increase from 127 to $162 \mathrm{~nm}$ and from 236 to $277 \mathrm{~nm}$ was attained, respectively. Even though the quantification of iron content in developed formulations was not determined, the obtained results clearly demonstrate that IONPs are indeed associated with liposomes. In addition, for all studied nanoformulations, the PDI was below 0.2 confirming the presence of monodispersed formulations. According to literature, these results further certify that IONPs are associated with the nanosystem and not in the free form [35]. Finally, and as previously observed (Table 1; Figure 4b), the presence of IONPs led to a higher percentage of liposomes after a short centrifugation cycle $(15,000 \mathrm{~g}, 30 \mathrm{~min})$ as demonstrated in Table 2 by the high \% of lipid: $59 \mathrm{vs.}$ 47 and 80 vs. 69 for LIP A and LIP B, respectively.

Table 2. Physicochemical parameters of Cuphen liposomes with different sizes (LIP A and LIP B) in the presence or absence of IONPs.

\begin{tabular}{|c|c|c|c|c|}
\hline Nanoformulation & $\begin{array}{c}\text { (Cuphen/Lip) } \\
\text { (nmol/ } \mu \mathrm{mol})\end{array}$ & $\begin{array}{c}(\text { Cuphen/Lip })_{\mathrm{f}} \\
(\mathrm{nmol} / \mu \mathrm{mol})\end{array}$ & $\begin{array}{c}\varnothing(\mathrm{nm}) \\
\text { (PDI) }\end{array}$ & Lipid in Pellet (\%) \\
\hline \multicolumn{5}{|l|}{ LIP A } \\
\hline With IONPS & $31 \pm 1$ & $22 \pm 1$ & $\begin{array}{c}162 \pm 1 \\
(<0.1)\end{array}$ & $59 \pm 1$ \\
\hline Without IONPs & $36 \pm 2$ & $26 \pm 1$ & $\begin{array}{l}127 \pm 1 \\
(<0.1)\end{array}$ & $47 \pm 2$ \\
\hline \multicolumn{5}{|l|}{ LIP B } \\
\hline With IONPs & $38 \pm 1$ & $25 \pm 1$ & $\begin{array}{c}277 \pm 1 \\
(<0.1)\end{array}$ & $80 \pm 3$ \\
\hline Without IONPs & $41 \pm 2$ & $35 \pm 1$ & $\begin{array}{c}236 \pm 4 \\
(<0.2)\end{array}$ & $69 \pm 2$ \\
\hline $\begin{array}{l}\text { Initial lipid con } \\
\text { Values are expresse }\end{array}$ & $\begin{array}{r}\text { ntration: } 30 \mu \mathrm{mo} \\
\text { Centrifuga } \\
\text { as average } \pm \text { SD } \\
\text { of liposomes }\end{array}$ & $\begin{array}{l}\text { mL. Initial Cuphe } \\
\text { n cycle: } 15,000 \mathrm{~g} \text {, } \\
\text { at least two inde } \\
\text { PDI: polydispersi }\end{array}$ & $\begin{array}{l}\text { oncentrat } \\
\text { min. } \\
\text { ident exp } \\
\text { index. }\end{array}$ & $\begin{array}{l}\text { n: } 750 \mathrm{nmol} / \mathrm{mL} \text {. } \\
\text { ments; Ø: mean size }\end{array}$ \\
\hline
\end{tabular}

\subsection{Validation of Magnetic Properties of the Developed Nanoformulations}

To ensure that Cuphen-loaded liposomes containing IONPs exhibited magnetic properties, a simple in vitro assay was carried out. Figure 5 shows the scheme of the prototype static model used. As described in the methods section, liposomes loading both Cuphen and IONPs were subjected to a magnetic field of $560.9 \mathrm{mT}$ for 1, 2, 6, and $19 \mathrm{~h}$ in separated assays. For each time point, samples were collected in both extremities of the well, and the Cuphen content was determined by spectrophotometry. The obtained data are depicted in Figure 6.

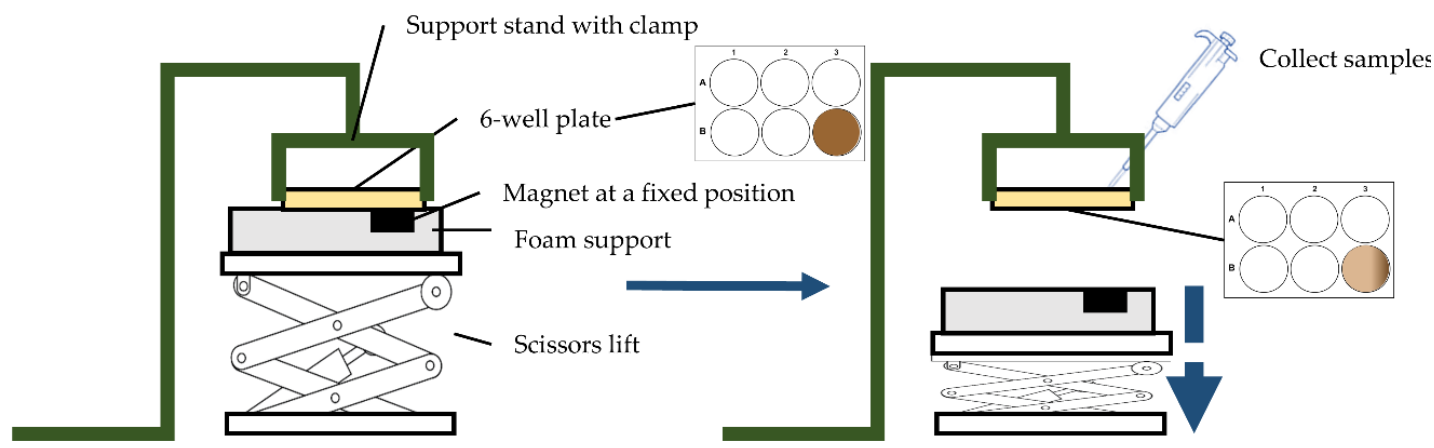

Figure 5. Scheme of the prototype static model used for validation of the magnetic properties of the developed nanoformulations. 


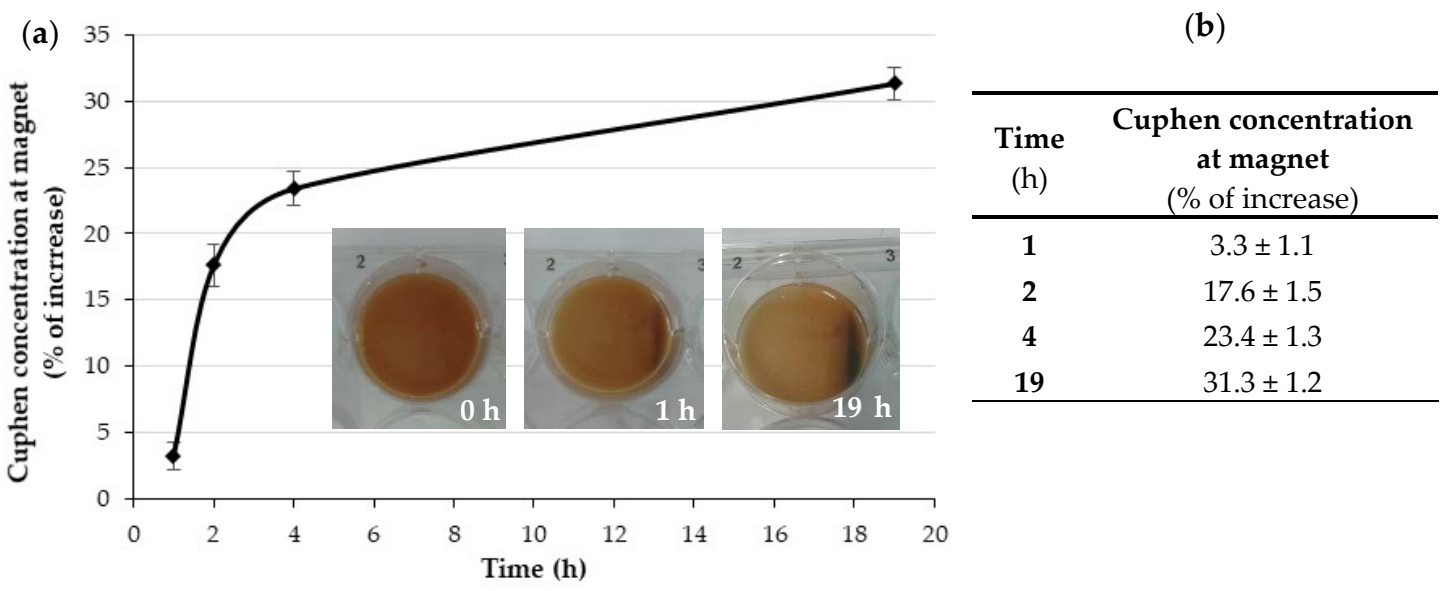

Figure 6. In vitro setup of the magnetic properties of Cuphen liposomes containing IONPs. (a) Graphical representation of Cuphen increase over time. Liposomes were exposed to a magnetic field of $560.9 \mathrm{mT}$; (b) Percentage of Cuphen increase at the magnet region. Results are expressed as average \pm SD of at least three independent experiments.

Results demonstrated that Cuphen liposomes with IONPs displayed magnetic properties following an exposure to a constant magnetic field, for up to $19 \mathrm{~h}$. This was a time-dependent effect, as an increase on Cuphen concentration (in \%) at the magnet site was observed over time. From 1 to $19 \mathrm{~h}$, a 10-fold increase on Cuphen accumulation was obtained.

\subsection{Hemocompatibility of Cuphen and IONPs}

Following the successful development and characterization of liposomes co-loading Cuphen and IONPs, the evaluation of the in vivo safety was performed by an hemolysis assay using human red blood cells (hRBCs) [8,31]. The tested formulations were free IONPs and liposomes co-loading Cuphen and IONPs. The obtained results are summarized in Table 3.

Table 3. Hemolytic activity of (a) free IONPs and (b) liposomes co-loading Cuphen and IONPs. Results are expressed as average $\pm \mathrm{SD}$.

\begin{tabular}{|c|c|c|c|c|c|}
\hline (a) & IONPs $(\mathrm{mg} / \mathrm{mL})$ & Hemolysis (\%) & (b) & Cuphen $(\mu \mathbf{M})$ & Hemolysis (\%) \\
\hline & 5.0 & $3.4 \pm 0.1$ & & 200.0 & $4.6 \pm 1.1$ \\
\hline & 2.5 & $1.6 \pm 0.3$ & & 100.0 & $3.5 \pm 0.5$ \\
\hline & 1.3 & $0.7 \pm 0.2$ & & 50.0 & $1.8 \pm 0.1$ \\
\hline & 0.6 & $0.2 \pm 0.1$ & & 25.0 & $0.9 \pm 0.2$ \\
\hline & 0.3 & 0.0 & & 12.5 & $0.4 \pm 0.2$ \\
\hline & & & & 6.3 & $0.3 \pm 0.3$ \\
\hline & & & & 3.1 & $0.2 \pm 0.2$ \\
\hline
\end{tabular}

The obtained data demonstrated that both formulations had negligible hemolytic effects $(<5 \%)$ at the tested concentrations, ranging from 0.313 to $5 \mathrm{mg} / \mathrm{mL}$ and 3.125 to $200 \mu \mathrm{M}$ for IONPs and Cuphen liposomes containing IONPs, respectively.

\section{Discussion}

Nanotechnology offers innovative tools to solve fundamental problems in cancer management, namely the efficient delivery of drugs to the diseased areas to maximize the therapeutic effect. Lipid-based systems, namely liposomes, are one of the most studied and successful delivery systems, with several examples already approved for use in the clinic, undergoing clinical trials or under preclinical development [36-38]. The present study focused on melanoma treatment through a novel hybrid lipid-based nanosystem. To this end, liposomes with magnetic properties were prepared by 
passively encapsulating IONPs within the aqueous interior compartment, a method that has been employed by other research groups [39-43].

The process to produce IONPs was modified to use Dextran-70 instead of Dextran-10, since according to Paul and co-workers [30], the use of Dextran-70 coated IONPs would result in IONPs with size $(21 \mathrm{~nm})$ and magnetic properties comparable to those using reduced Dextran-10. The main advantage of this modified method would be to skip the $12 \mathrm{~h}$ step for Dextran reduction, a highly time-consuming reaction. If successful, the applied modifications in the protocol would allow for a faster and simpler IONPs production via a microwave-assisted reaction. The microscopic analysis of coated and uncoated IONPs clearly demonstrated the benefits of the coating, as uncoated IONPs presented more aggregation and a larger iron core, compared to the coated ones. Aggregation was expected, since the IONPs high surface area to volume ratio renders them especially vulnerable to Van der Waals forces [44]. Furthermore, other factors associated with the suspension medium, including charge shielding effects in saline buffers or protein adsorption in biological medium, may contribute to aggregation [45]. On the other hand, Dextran-70 coated IONPs displayed a more disperse morphology and well-defined IONPs. The obtained images are according to the research published by Osborne and colleagues [29], where TEM imaging of Dextran coated IONPs should show only the iron cores, since Dextran would be transparent in TEM [29]. DLS assays were also performed and the obtained hydrodynamic size of coated IONPs corroborated data obtained from microscopic analysis.

The main goal of this study was to develop liposomes with cytotoxic (Cuphen) and magnetic (IONPs) properties. Considering their physical and chemical properties, IONPs can be used either as part of the tumor treatment (e.g.,: hyperthermia and photodynamic therapy), or for the magnetic targeting of nanosystems carrying the therapeutic drug [27,46,47]. In clinical practice, the potential cytotoxicity evaluation of IONPs is a major priority in order to avoid unpredictable interactions that could lead to unwanted side effects [47]. Few in vitro studies have been published and are often inconsistent, in vivo assays are scarce and human studies are almost inexistent. A balance between benefit and risk has to be carefully considered for each specific application [28,48-51]. Nevertheless, in the present research, two main aspects were taken into consideration when developing this hybrid nanosystem: (i) IONPs should not, by themselves, affect cell viability and (ii) IONPs presence should not influence Cuphen cytotoxicity towards tumoral cells. Using murine and human melanoma cell lines, cell viability studies showed that Cuphen cytotoxicity was preserved in the presence of IONPs. Moreover, IONPs at $2 \mathrm{mg} / \mathrm{mL}$ proved to be innocuous, in terms of cellular viability, and so this was hence the selected concentration to be used for the preparation of the hybrid nanosystem co-loading Cuphen and IONPs.

The magnetic properties of Cuphen liposomes loading IONPs were confirmed. The proof of concept was performed by exposing the hybrid nanosystem at constant magnetic field of $560.9 \mathrm{mT}$ for each analysed time. This assay allowed to confirm that an accumulation of Cuphen at the magnet site was achieved, being time dependent.

The absence of hemolytic activity of IONPs, after incubation with human red blood cells (hRBCs), revealed their suitability for parenteral administration. In vivo studies in a syngeneic melanoma model comparing the antitumor effect of Cuphen liposomes and the hybrid nanosystem co-incorporating IONPs should be envisioned in the near future.

\section{Conclusions}

Considering these preliminary data, the synthetized IONPs are safe for parenteral administration. Moreover, they did not interfere with cytotoxic activity of the metallodrug and when co-associated with Cuphen liposomes demonstrated magnetic properties. Further research involving a syngeneic murine melanoma model should be carried out to validate the effectiveness of this novel hybrid nanosystem and the potential therapeutic improvement of Cuphen liposomes.

Author Contributions: Conceptualization, C.R., M.M.G. and N.M.; formal analysis, N.C., J.O.P., G.S., L.A., N.M., C.R. and M.M.G.; writing-original draft preparation, N.C. and J.O.P.; writing-review and editing, N.C., J.O.P., 
G.S., L.A., N.M., C.R. and M.M.G.; funding acquisition, G.S., N.M., C.R. and M.M.G. All authors have read and agreed to the published version of the manuscript.

Funding: This research was funded by Fundação para a Ciência e a Tecnologia (FCT) through the projects: UID/DTP/04138/2019, PTDC/BTM-SAL/28977/2017, PTDC/MED-QUI/31721/2017 and UIDB/00645/2020 as well as by the PhD fellowship SFRH/BD/117586/2016. The research was also funded to CESAM, (UID/AMB/50017/2019), through FCT/MEC National funds, and co-funding by FEDER, within the PT2020 Partnership Agreement and Compete 2020.

Acknowledgments: The authors would like to acknowledge Adília J. Charmier from the DREAMS research group of Universidade Lusófona de Humanidades e Tecnologias (Lisboa, Portugal) for allowing the use of microwaves for the production of IONPs.

Conflicts of Interest: The authors declare no conflict of interest.

\section{References}

1. Schadendorf, D.; Fisher, D.E.; Garbe, C.; Gershenwald, J.E.; Grob, J.-J.J.; Halpern, A.; Herlyn, M.; Marchetti, M.A.; McArthur, G.; Ribas, A.; et al. Melanoma. Nat. Rev. Dis. Prim. 2015, 1, 15003. [CrossRef] [PubMed]

2. Dickens, E.; Ahmed, S. Principles of cancer treatment by chemotherapy. Surg 2018, 36, 134-138. [CrossRef]

3. Balch, C.M.; Gershenwald, J.E.; Soong, S.J.; Thompson, J.F.; Atkins, M.B.; Byrd, D.R.; Buzaid, A.C.; Cochran, A.J.; Coit, D.G.; Ding, S.; et al. Final version of 2009 AJCC melanoma staging and classification. J. Clin. Oncol. 2009, 27, 6199-6206. [CrossRef] [PubMed]

4. Korn, E.L.; Liu, P.Y.; Lee, S.J.; Chapman, J.A.W.; Niedzwiecki, D.; Suman, V.J.; Moon, J.; Sondak, V.K.; Atkins, M.B.; Eisenhauer, E.A.; et al. Meta-analysis of phase II cooperative group trials in metastatic stage IV melanoma to determine progression-free and overall survival benchmarks for future phase II trials. J. Clin. Oncol. 2008, 26, 527-534. [CrossRef] [PubMed]

5. Garbe, C.; Eigentler, T.K.; Keilholz, U.; Hauschild, A.; Kirkwood, J.M. Systematic Review of Medical Treatment in Melanoma: Current Status and Future Prospects. Oncologist 2011, 16, 5-24. [CrossRef] [PubMed]

6. Pasquali, S.; Hadjinicolaou, A.V.; Chiarion Sileni, V.; Rossi, C.R.; Mocellin, S. Systemic treatments for metastatic cutaneous melanoma. Cochrane Database Syst. Rev. 2018, 2, CD011123. [CrossRef]

7. Arnesano, F.; Natile, G. Mechanistic insight into the cellular uptake and processing of cisplatin 30 years after its approval by FDA. Coord. Chem. Rev. 2009, 253, 2070-2081. [CrossRef]

8. Nave, M.; Castro, R.E.; Rodrigues, C.M.; Casini, A.; Soveral, G.; Gaspar, M.M. Nanoformulations of a potent copper-based aquaporin inhibitor with cytotoxic effect against cancer cells. Nanomedicine 2016, 11, 1817-1830. [CrossRef]

9. Pinho, J.O.; Amaral, J.D.; Castro, R.E.; Rodrigues, C.M.P.; Casini, A.; Soveral, G.; Gaspar, M.M. Copper complex nanoformulations featuring highly promising therapeutic potential in murine melanoma models. Nanomedicine 2019, 14, 835-850. [CrossRef]

10. Martins, A.P.; Marrone, A.; Ciancetta, A.; Galán Cobo, A.; Echevarría, M.; Moura, T.F.; Re, N.; Casini, A.; Soveral, G. Targeting Aquaporin Function: Potent Inhibition of Aquaglyceroporin-3 by a Gold-Based Compound. PLoS ONE 2012, 7, e37435. [CrossRef]

11. Wenzel, M.N.; Mósca, A.F.; Graziani, V.; Aikman, B.; Thomas, S.R.; de Almeida, A.; Platts, J.A.; Re, N.; Coletti, C.; Marrone, A.; et al. Insights into the Mechanisms of Aquaporin-3 Inhibition by Gold(III) Complexes: The Importance of Non-Coordinative Adduct Formation. Inorg. Chem. 2019, 58, 2140-2148. [CrossRef] [PubMed]

12. Soveral, G.; Nielsen, S.; Casini, A. Aquaporins in Health and Disease: New Molecular Targets for Drug Discovery; CRC Press, Taylor \& Francis Group: Boca Raton, FL, USA, 2016; ISBN 9781498782579.

13. de Almeida, A.; Mósca, A.F.; Wragg, D.; Wenzel, M.; Kavanagh, P.; Barone, G.; Leoni, S.; Soveral, G.; Casini, A. The mechanism of aquaporin inhibition by gnold compounds elucidated by biophysical and computational methods. Chem. Commun. 2017, 53, 3830-3833. [CrossRef] [PubMed]

14. Soveral, G.; Casini, A. Aquaporin modulators: A patent review (2010-2015). Expert Opin. Ther. Pat. 2017, 27, 49-62. [CrossRef] [PubMed]

15. de Almeida, A.; Soveral, G.; Casini, A. Gold compounds as aquaporin inhibitors: New opportunities for therapy and imaging. Medchemcomm 2014, 5, 1444-1453. [CrossRef]

16. Bales, B.C. Mechanistic studies on DNA damage by minor groove binding copper-phenanthroline conjugates. Nucleic Acids Res. 2005, 33, 5371-5379. [CrossRef] 
17. Papadopoulos, M.C.; Saadoun, S. Key roles of aquaporins in tumor biology. Biochim. Biophys. Acta Biomembr. 2015, 1848, 2576-2583. [CrossRef]

18. Martins, A.P.; Ciancetta, A.; de Almeida, A.; Marrone, A.; Re, N.; Soveral, G.; Casini, A. Aquaporin inhibition by gold(III) compounds: New insights. ChemMedChem 2013, 8, 1086-1092. [CrossRef]

19. Deshpande, P.P.; Biswas, S.; Torchilin, V.P. Current trends in the use of liposomes for tumor targeting. Nanomedicine 2013, 8, 1509-1528. [CrossRef]

20. Belfiore, L.; Saunders, D.N.; Ranson, M.; Thurecht, K.J.; Storm, G.; Vine, K.L. Towards clinical translation of ligand-functionalized liposomes in targeted cancer therapy: Challenges and opportunities. J. Control. Release 2018, 277, 1-13. [CrossRef]

21. Maeda, H.; Nakamura, H.; Fang, J. The EPR effect for macromolecular drug delivery to solid tumors: Improvement of tumor uptake, lowering of systemic toxicity, and distinct tumor imaging in vivo. Adv. Drug Deliv. Rev. 2013, 65, 71-79. [CrossRef]

22. Duan, Y.; Wei, L.; Petryk, J.; Ruddy, T.D. Formulation, characterization and tissue distribution of a novel $\mathrm{pH}$-sensitive long-circulating liposome-based theranostic suitable for molecular imaging and drug delivery. Int. J. Nanomed. 2016, 11, 5697-5708. [CrossRef] [PubMed]

23. Persi, E.; Duran-Frigola, M.; Damaghi, M.; Roush, W.R.; Aloy, P.; Cleveland, J.L.; Gillies, R.J.; Ruppin, E. Systems analysis of intracellular pH vulnerabilities for cancer therapy. Nat. Commun. 2018, 9, 2997. [CrossRef] [PubMed]

24. Bañobre-López, M.; Teijeiro, A.; Rivas, J. Magnetic nanoparticle-based hyperthermia for cancer treatment. Rep. Pract. Oncol. Radiother. 2013, 18, 397-400. [CrossRef] [PubMed]

25. Kim, T.H.; Lee, S.; Chen, X. Nanotheranostics for personalized medicine. Expert Rev. Mol. Diagn. 2013, 13, 257-269. [CrossRef]

26. El-Boubbou, K. Magnetic iron oxide nanoparticles as drug carriers: Clinical relevance. Nanomedicine 2018, 13, 953-971. [CrossRef]

27. Price, D.N.; Stromberg, L.R.; Kunda, N.K.; Muttil, P. In Vivo Pulmonary Delivery and Magnetic-Targeting of Dry Powder Nano-in-Microparticles. Mol. Pharm. 2017, 14, 4741-4750. [CrossRef] [PubMed]

28. Vakili-Ghartavol, R.; Momtazi-Borojeni, A.A.; Vakili-Ghartavol, Z.; Aiyelabegan, H.T.; Jaafari, M.R.; Rezayat, S.M.; Arbabi Bidgoli, S. Toxicity assessment of superparamagnetic iron oxide nanoparticles in different tissues. Artif. Cells Nanomed. Biotechnol. 2020, 48, 443-451. [CrossRef]

29. Osborne, E.A.; Atkins, T.M.; Gilbert, D.A.; Kauzlarich, S.M.; Liu, K.; Louie, A.Y. Rapid microwave-assisted synthesis of dextran-coated iron oxide nanoparticles for magnetic resonance imaging. Nanotechnology 2012, 23, 215602. [CrossRef]

30. Paul, K.G.; Frigo, T.B.; Groman, J.Y.; Groman, E. V Synthesis of Ultrasmall Superparamagnetic Iron Oxides Using Reduced Polysaccharides. Bioconjug. Chem. 2004, 15, 394-401. [CrossRef]

31. Gaspar, M.M.; Calado, S.; Pereira, J.; Ferronha, H.; Correia, I.; Castro, H.; Tomás, A.M.; Cruz, M.E.M. Targeted delivery of paromomycin in murine infectious diseases through association to nano lipid systems. Nanomed. Nanotechnol. Biol. Med. 2015, 11, 1851-1860. [CrossRef]

32. Lasch, J.; Weissig, V.; Brandl, M. Preparation of Liposomes. In Liposomes: A Practical Approach; Vladimir, T., Weissig, V., Eds.; Oxford University Press: New York, NY, USA, 2003; pp. 3-27.

33. Rouser, G.; Fleischer, S.; Yamamoto, A. Two dimensional thin layer chromatographic separation of polar lipids and determination of phospholipids by phosphorus analysis of spots. Lipids 1970, 5, 494-496. [CrossRef] [PubMed]

34. Oliveira, V.R.; Uriarte, J.J.; Falcones, B.; Jorba, I.; Zin, W.A.; Farré, R.; Navajas, D.; Almendros, I. Biomechanical Response of Lung Epithelial Cells to Iron Oxide and Titanium Dioxide Nanoparticles. Front. Physiol. 2019, 10, 1047. [CrossRef] [PubMed]

35. Mota-Cobián, A.; Velasco, C.; Mateo, J.; España, S. Optimization of purification techniques for lumen-loaded magnetoliposomes. Nanotechnology 2020, 31, 145102. [CrossRef] [PubMed]

36. Bulbake, U.; Doppalapudi, S.; Kommineni, N.; Khan, W. Liposomal Formulations in Clinical Use: An Updated Review. Pharmaceutics 2017, 9, 12. [CrossRef]

37. Silva, C.O.; Pinho, J.O.; Lopes, J.M.; Almeida, A.J.; Gaspar, M.M.; Reis, C. Current Trends in Cancer Nanotheranostics: Metallic, Polymeric, and Lipid-Based Systems. Pharmaceutics 2019, 11, 22. [CrossRef]

38. Oliveira Pinho, J.; Matias, M.; Gaspar, M.M. Emergent Nanotechnological Strategies for Systemic Chemotherapy against Melanoma. Nanomaterials 2019, 9, 1455. [CrossRef] 
39. Martina, M.-S.; Fortin, J.-P.; Ménager, C.; Clément, O.; Barratt, G.; Grabielle-Madelmont, C.; Gazeau, F.; Cabuil, V.; Lesieur, S. Generation of superparamagnetic liposomes revealed as highly efficient MRI contrast agents for in vivo imaging. J. Am. Chem. Soc. 2005, 127, 10676-10685. [CrossRef]

40. Fortes Brollo, M.E.; Domínguez-Bajo, A.; Tabero, A.; Domínguez-Arca, V.; Gisbert, V.; Prieto, G.; Johansson, C.; Garcia, R.; Villanueva, A.; Serrano, M.C.; et al. Combined Magnetoliposome Formation and Drug Loading in One Step for Efficient Alternating Current-Magnetic Field Remote-Controlled Drug Release. ACS Appl. Mater. Interfaces 2020, 12, 4295-4307. [CrossRef]

41. Cintra, E.R.; Ferreira, F.S.; Santos Junior, J.L.; Campello, J.C.; Socolovsky, L.M.; Lima, E.M.; Bakuzis, A.F. Nanoparticle agglomerates in magnetoliposomes. Nanotechnology 2009, 20, 045103. [CrossRef]

42. Pradhan, P.; Giri, J.; Rieken, F.; Koch, C.; Mykhaylyk, O.; Döblinger, M.; Banerjee, R.; Bahadur, D.; Plank, C. Targeted temperature sensitive magnetic liposomes for thermo-chemotherapy. J. Control. Release 2010, 142, 108-121. [CrossRef]

43. Skouras, A.; Mourtas, S.; Markoutsa, E.; De Goltstein, M.-C.; Wallon, C.; Catoen, S.; Antimisiaris, S.G. Magnetoliposomes with high USPIO entrapping efficiency, stability and magnetic properties. Nanomed. Nanotechnol. Biol. Med. 2011, 7, 572-579. [CrossRef]

44. Zhang, W. Nanoparticle aggregation: Principles and modeling. Adv. Exp. Med. Biol. 2014, 811, 19-43. [PubMed]

45. Etheridge, M.L.; Hurley, K.R.; Zhang, J.; Jeon, S.; Ring, H.L.; Hogan, C.; Haynes, C.L.; Garwood, M.; Bischof, J.C. Accounting for biological aggregation in heating and imaging of magnetic nanoparticles. Technology 2014, 02, 214-228. [CrossRef] [PubMed]

46. Hu, Y.; Mignani, S.; Majoral, J.-P.; Shen, M.; Shi, X. Construction of iron oxide nanoparticle-based hybrid platforms for tumor imaging and therapy. Chem. Soc. Rev. 2018, 47, 1874-1900. [CrossRef] [PubMed]

47. Mustafa, T.A.; Mohammed-Rasheed, M.A. Accumulation and cytotoxicity assessment of TAT-IONPs on cancerous mammalian cells. Anim. Biotechnol. 2019, 1-6. [CrossRef] [PubMed]

48. Valdiglesias, V.; Fernández-Bertólez, N.; Kiliç, G.; Costa, C.; Costa, S.; Fraga, S.; Bessa, M.J.; Pásaro, E.; Teixeira, J.P.; Laffon, B. Are iron oxide nanoparticles safe? Current knowledge and future perspectives. J. Trace Elem. Med. Biol. 2016, 38, 53-63. [CrossRef] [PubMed]

49. Okon, E.E.; Pulikan, D.; Pereverzev, A.E.; Kudriavtsev, B.N.; Zhale, P. Toxicity of magnetite-dextran particles: Morphological study. Tsitologiia 2000, 42, 358-366.

50. Al-Jamal, K.T.; Bai, J.; Wang, J.T.-W.; Protti, A.; Southern, P.; Bogart, L.; Heidari, H.; Li, X.; Cakebread, A.; Asker, D.; et al. Magnetic Drug Targeting: Preclinical in Vivo Studies, Mathematical Modeling, and Extrapolation to Humans. Nano Lett. 2016, 16, 5652-5660. [CrossRef]

51. Naqvi, S.; Samim, M.; Abdin, M.Z.; Ahmed, F.J.; Maitra, A.N.; Prashant, C.K.; Dinda, A.K. Concentrationdependent toxicity of iron oxide nanoparticles mediated by increased oxidative stress. Int. J. Nanomed. 2010, 5,983 .

(C) 2020 by the authors. Licensee MDPI, Basel, Switzerland. This article is an open access article distributed under the terms and conditions of the Creative Commons Attribution (CC BY) license (http://creativecommons.org/licenses/by/4.0/). 